\title{
Expediency of abdominal drainage after operative delivery in severe preeclampsia
}

Prof. Protopopova N. V., V. A. Kramarsky*

State budgetary educational institution of additional medical education Irkutsk state medical Academy of postgraduate education. Department of obstetrics and gynecology.

*Corresponding Author: V. A. Kramarsky, State budgetary educational institution of additional medical education Irkutsk state medical Academy of postgraduate education. Department of obstetrics and gynecology.

Received date: August 24, 2020; Accepted date: October 23, 2020; Published date: November 03, 2020

Citation: Miguel Oliveros Donohue (2020) Expediency of abdominal drainage after operative delivery in severe preeclampsia. J Obstetrics Gynecology and Reproductive Sciences. 4(3); DOI: 10.31579/ 2578-8965/052

copyright: ( 2020 Miguel Oliveros Donohue, This is an open-access article distributed under the terms of the Creative Commons Attribution License, which permits unrestricted use, distribution, and reproduction in any medium, provided the original author and source are credited.

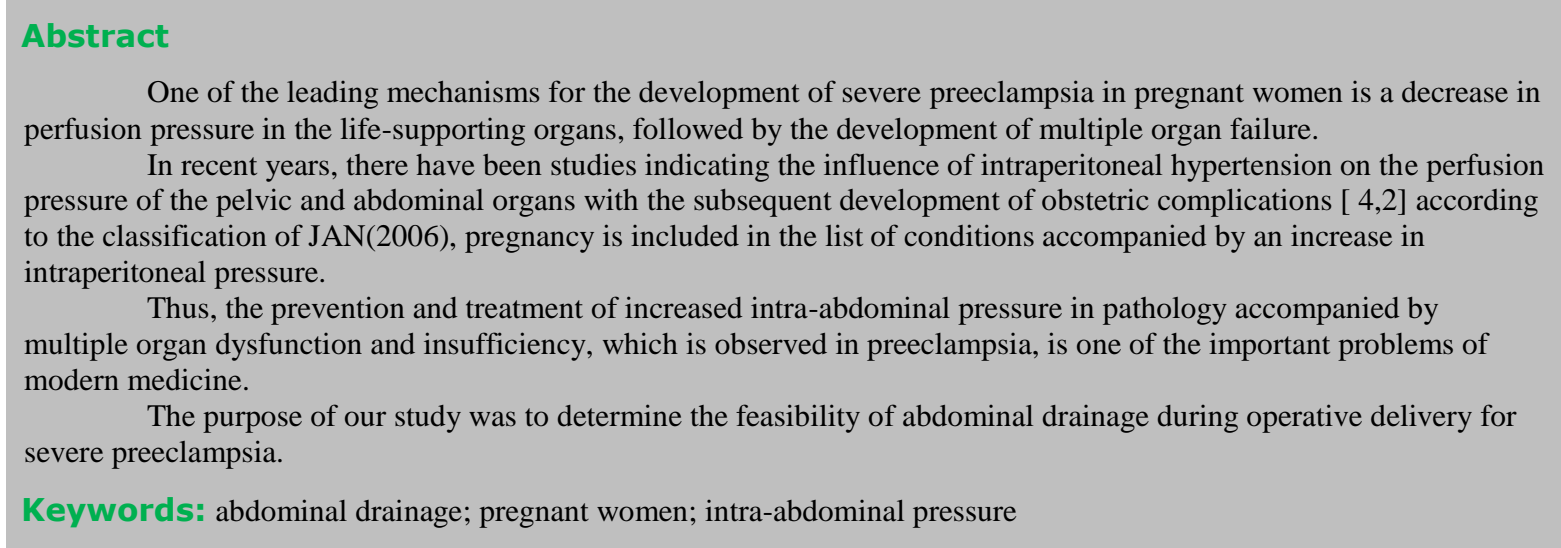

\section{Introduction}

One of the leading mechanisms for the development of severe preeclampsia in pregnant women is a decrease in perfusion pressure in the life-supporting organs, followed by the development of multiple organ failure.

In recent years, there have been studies indicating the influence of intraperitoneal hypertension on the perfusion pressure of the pelvic and abdominal organs with the subsequent development of obstetric complications [ 4,2] according to the classification of JAN(2006), pregnancy is included in the list of conditions accompanied by an increase in intraperitoneal pressure.

Thus, the prevention and treatment of increased intraabdominal pressure in pathology accompanied by multiple organ dysfunction and insufficiency, which is observed in preeclampsia, is one of the important problems of modern medicine.

The purpose of our study was to determine the feasibility of abdominal drainage during operative delivery for severe preeclampsia.

\section{Material and methods of research}

Retrospectively, three groups of women after cesarean section for severe preeclampsia with abdominal drainage (28 people-group 1 ), without abdominal drainage (36 people-group 2) and operated preemptively in a planned manner for complex indications (30 peoplegroup 3) were studied by random sampling. The study group excluded women with a pronounced degree of increased nutrition, postpartum bleeding and uterine tumour (fibroids).

The average pregnancy period in the second group of women without abdominal drainage was $34.7 \pm 2.3$ weeks, in the first group with a drained abdominal cavity $34.5 \pm 3.4$ weeks. and in the group of women without preeclampsia $38.2 \pm 1.8$ weeks. The average age in the study groups of maternity women was $24.1 \pm 2.6$ years, $21.1 \pm 1.7$ years and $26.3 \pm 3.3$ years, respectively. Parity among the studied maternity hospitals was distributed as follows: in the second group, there were 15 repeat pregnancies $(41.7 \%)$. there were $4(11.1 \%)$ repeat births, $26(92.8 \%)$ and $15(53.6 \%)$ in the first group, and 30(100\%) and 19(63.3\%) in the third group, respectively. Thus, both the average age and the parity in the groups of maternity women with preeclampsia did not differ significantly.

Due to the presence of a pronounced form of preeclampsia in the postoperative period, women in the first and second groups received intravenous magnesia therapy at the rate of an average of $1.6 \pm 0.6 \mathrm{~g} / \mathrm{h}$. not exceeding 24 grams per day under the control of diuresis, peripheral reflexes, respiratory rate and the level of magnesium in the patient's blood serum.

The average duration of surgery in the first group of women was 43.6 \pm 5.8 minutes, in the second $38.2 \pm 6.4$ minutes and in the third $36.5 \pm 3.5$ minutes. And did not differ significantly $(\mathrm{P} \geq 0.05)$. The average blood loss in the first and second groups of women did not differ significantly $(\mathrm{P} \leq 0.05)$, amounting to $568.9 \pm 56.7 \mathrm{ml}$ and $623.4 \pm 68.2 \mathrm{ml}$, respectively, but was significantly greater $(\mathrm{P} \leq 0.01)$ than the third group 
of women with physiologically occurring pregnancy, which averaged $342.8 \pm 46.3 \mathrm{ml}$.

The average score of newborns at the first minute on the Apgar scale in the first group of women was $5.5 \pm 0.4$ points, in the second group $6.2 \pm 0.6$ points and in the third group $8.6 \pm 0.5$ points, significantly not differing $(\mathrm{P} \geq 0.01)$ between the indicators of the first and second groups and significantly differing $(\mathrm{P} \leq 0.05)$ from the indicators in the third group of women. The average weight of newborns in the considered groups of women had the same pattern in a significant difference. Thus, the average weight of newborns in the first group of women was $1658.6 \pm 68.4$ grams, in the second group 1753.8 \pm 37.6 grams and in the third group of women $3658.1 \pm 47.9$ grams.

There were no cases of perinatal mortality of newborns in any of the observations.

In the first group of women, the abdominal cavity was drained through the main incision with a PVC drainage system for intravenous drip fluid transfusions. In all these observations, drainage was performed due to the presence of light fluid in the abdominal cavity in a volume of 300 to 700 $\mathrm{ml}$, which was on average $340.6 \pm 186.4 \mathrm{ml}$.

Intraperitoneal pressure was determined on the first day after the operation no earlier than 3 hours after its completion To translate intraperitoneal pressure (IAP) in centimeters of mercury column, the result was divided by 1.36.(1) the calculation of perfusion pressure of the abdominal organs was carried out using the formula: the indicator of average blood pressure was divided by the indicator of intraperitoneal pressure. Normal perfusion pressure should be at least $50 \mathrm{mmHg}$.

\section{Research result:}

As a result of the study, it was noted that the average IHD after cesarean section in the group of women who did not have preeclampsia (30 people-1 group) was equal to $13.2 \pm 2.1 \mathrm{~mm} \mathrm{Hg}$.or in terms of millimeters of mercury, $9.7 \pm 1.5 \mathrm{~mm} \mathrm{Hg}$. with a range from 8.2 to 11.1 $\mathrm{mm} \mathrm{Hg}$.

In the group of women with a pronounced degree of preeclampsia ( 36 people-group 2), for which operative delivery was performed, the average IHD was respectively equal to $26.4 \pm 1.9 \mathrm{~mm} \mathrm{Hg}$, or $19.4 \pm 1.7 \mathrm{~mm} \mathrm{Hg}$ with a range of 10 to $15 \mathrm{~mm} \mathrm{Hg}$, or 8 to $11 \mathrm{~mm} \mathrm{Hg}$, and was significantly higher $(\mathrm{P} \leq 0.05)$ than in the group of women without preeclampsia.

In women with severe preeclampsia, but drained abdominal cavity (28 people-group 3), similar indicators were respectively equal to $15.9 \pm 2.3 \mathrm{~mm} \mathrm{Hg}$, or $11.7 \pm 2.1 \mathrm{~mm} \mathrm{Hg}$, with a range of $11 \mathrm{~mm} \mathrm{Hg}$ or 9 to $13 \mathrm{~mm} \mathrm{Hg}$, and were significantly less $(\mathrm{P} \leq 0.05)$ than in women with severe preeclampsia, but without abdominal drainage. At the same time, the indicators of IHD during abdominal drainage with severe preeclampsia and similar indicators among women whose pregnancy was not complicated by preeclampsia did not differ significantly $(\mathrm{P} \geq 0.05)$.

Evaluation of hourly diuresis as an indirect indicator of kidney perfusion capacity confirmed the feasibility of abdominal drainage in preeclampsia of a pronounced degree and operative delivery.

Thus, the hourly diuresis in the first and third groups of women were equal to $45.3 \pm 5.6 \mathrm{ml} /$ hour and $51.2 \pm 3.8 \mathrm{ml} /$ hour, respectively, and did not differ significantly ( $p>0.01)$, and in the second group of women with preeclampsia and lack of abdominal drainage, the average hourly diuresis was equal to $34.6 \pm 2.7 \mathrm{ml} /$ hour. and was significantly lower $(\mathrm{P}<0.01)$ than in the first and third groups of women.

The results obtained gave grounds to assert the feasibility of drainage of the abdominal cavity in severe preeclampsia, not only to remove fluid from the abdominal cavity, but also to reduce IHD, which should have been accompanied by an improvement in the perfusion of the abdominal organs.

\section{Conclusions:}

1 IHD in preeclampsia significantly exceeds IHD in women whose pregnancy was not complicated by preeclampsia.

2. abdominal drainage after surgery cesarean section for severe preeclampsia significantly reduces IHD compared to women whose pregnancy was also complicated by preeclampsia, but after operative delivery, abdominal drainage was not performed

3. drainage of the abdominal cavity is an appropriate manipulation aimed at reducing IHD.

\section{References}

1. Kulikov L. S., Sobotovich V. F., Privalov Yu. a. Compartment syndrome in surgical practice-method of recommendation, IGMAPO, 2010, 26C.

2. Kramarsky V. A., Kuzakov I. S., Dementiev K. A., Brodyansky S. A., Volkov A. B., Kochetkova E. V. Intraperitoneal hypertension and perfusion pressure level in women with preeclampsia of various severity after cesarean section. Anesthesiology and resuscitation. 2013; 5: 21-22.

3. malanina E. N., Davydyan L. Yu. Assessment of Doppler markers of intraabdominal hypertension-M., forum "Mother and child", 2012,, Pp. 103-104.

4. Marshalov D. V., Salov I. A., Petrenko A. P. Tarasenko Yu. N. the Role of intraperitoneal hypertension in the severity of endotoxicosis in $p$ 